\title{
Pulmonary delivery of cisplatin-hyaluronan conjugates via endotracheal instillation for the treatment of lung cancer
}

\author{
Yumei Xie $^{\mathrm{a}}$, Kristin L. Aillon ${ }^{\mathrm{a}}$, Shuang Cai ${ }^{\mathrm{a}}$, Jason M. Christian ${ }^{\mathrm{b}}$, Neal M. Davies ${ }^{\mathrm{C}}$, Cory J. \\ Berkland $^{a, b}$, and $\mathbf{M}$. Laird Forrest ${ }^{a}{ }^{*}$ \\ aDepartment of Pharmaceutical Chemistry, University of Kansas, Lawrence, KS, 66047 USA \\ bDepartment of Chemical and Petroleum Engineering, University of Kansas, Lawrence, KS, 66047 \\ USA \\ 'Department of Pharmaceutical Sciences, Washington State University, Pullman, WA, 99164 USA
}

\section{Abstract}

Cisplatin (CDDP) intravenous treatments suffer several dose-limiting toxicity issues. Hyaluronan (HA), a naturally occurring biopolymer in the interstitium, is primarily cleared by the lymphatic system. An alteration in input rate and administration route through pulmonary delivery of hyaluronan-cisplatin conjugate (HA-Pt) may increase local lung CDDP concentrations and decrease systemic toxicity.

Sprague-Dawley rats were split into four groups: i.v. CDDP $(3.5 \mathrm{mg} / \mathrm{kg})$, i.v. HA-Pt conjugate $(3.5$ $\mathrm{mg} / \mathrm{kg}$ equivalent CDDP), lung instillation CDDP and lung instillation HA-Pt conjugate. Total platinum level in the lungs of the HA-Pt lung instillation group was 5.7-fold and 1.2-fold higher than the CDDP intravenous group at $24 \mathrm{~h}$ and $96 \mathrm{~h}$, respectively. A 1.1-fold increase of Pt accumulation in lung draining nodes for the HA-Pt lung instillation group was achieved at $24 \mathrm{~h}$ relative to the CDDP i.v. group. In the brain and kidneys, the CDDP i.v. group had higher tissue/plasma ratios compared to the HA-Pt lung instillation group. Augmented tissue distribution from CDDP i.v. could translate into enhanced tissue toxicity compared to the altered input rate and distribution of the intrapulmonary nanoformulation.

In conclusion, a local pulmonary CDDP delivery system was developed with increased platinum concentration in the lungs and draining nodes compared to i.v. therapy.

\section{Keywords}

cisplatin; hyaluronan; pharmacokinetics; pulmonary delivery; lung chemotherapeutics

\section{Introduction}

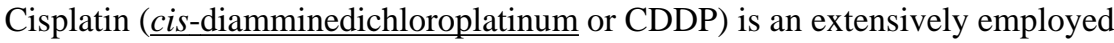
chemotherapeutic agent for the treatment of a wide spectrum of solid tumors. CDDP-based

\footnotetext{
(C) 2010 Elsevier B.V. All rights reserved

*Corresponding author at: 2095 Constant Ave., Lawrence, KS, 66047 USA. Tel.: +1 785864 4388; fax: + 17858645736. mforrest@ku.edu.

Publisher's Disclaimer: This is a PDF file of an unedited manuscript that has been accepted for publication. As a service to our customers we are providing this early version of the manuscript. The manuscript will undergo copyediting, typesetting, and review of the resulting proof before it is published in its final citable form. Please note that during the production process errors may be discovered which could affect the content, and all legal disclaimers that apply to the journal pertain.
} 
therapies have been shown to be more effective in the treatment of lung cancer compared to other platinum chemotherapeutics, such as carboplatin (Hotta et al., 2004; Zatloukal et al., 2003). However, CDDP administered intravenously can cause severe side effects including increased risks of leucopenia, nausea, anemia, acute nephrotoxicity, and chronic neurotoxicity (both hearing loss and nerve damage) (Carrick et al., 2004; Chu, 1994; Ihde et al., 1994; Perng et al., 1997). These detrimental side effects can lead to decreased patient compliance, inability to complete chemotherapy courses, or use of less effective chemotherapeutic agents. Moreover, untargeted chemotherapeutics that are delivered intravenously result in relatively low concentrations of drug that reaches the lung tumor compared to cytotoxin susceptible tissues and organs. This ultimately decreases the chances of successful control of the tumor and increases the risks of adverse toxicity events in patients due to wide distribution of the drug.

Many efforts have been made to reduce the systemic side effects while retaining the potency of CDDP in treatment regimens including: combination therapy, encapsulation of CDDP in liposomes (Kim et al., 2001) and micelles (Nishiyama et al., 2003), and regional delivery of CDDP by pulmonary arterial infusion (Brown et al., 2006; Devarajan et al., 2004; Junior et al., 2007). Pulmonary delivery of chemotherapeutics has become of topical interest as a noninvasive route of administration for local delivery to the lungs (Gagnadoux et al., 2008; Selting et al., 2008). This route of administration may increase drug concentration in the lungs and reduce overall systemic side effects, which could greatly benefit both early stage patients with locoregional disease and advanced patients requiring less harmful palliative care.

Localization of drug not only to the cancerous cells, but also to the surrounding lymph nodes is essential in treatment and prevention of cancer cell metastasis. Hyaluronan (HA) is a naturally occurring polysaccharide found in the connective tissues and is primarily cleared by the lymphatic system (Fraser and Laurent, 1989). Conjugation of CDDP to HA may result in localization of CDDP to the lymph nodes. Our previous studies have shown successful drainage of hyaluronan-cisplatin (HA-Pt) conjugates into the axillary lymph nodes with reduced systemic toxicities after local injection in a breast cancer xenograft model in rodents (Cai et al., 2008).

Pulmonary delivery of the HA-Pt conjugate to the lungs may be useful in the treatment of lung cancer by reducing systemic toxicities and increasing CDDP deposition and retention within lung tumors, surrounding lung tissues, and the mediastinal lymph. The purpose of this study was to determine the pharmacokinetics and tissue distribution of a pulmonary delivered HAPt conjugate relative to CDDP and compare these results to CDDP or HA-Pt conjugate delivered intravenously.

\section{Materials and Methods}

\subsection{Materials}

Hyaluronan as sodium hyaluronate was purchased from Lifecore Biomedical (Chaska, MN); All other reagents were purchased from Sigma Chemical Co. or Fisher Scientific (Waltham, MA) and used without further purification. Human lung adenocarcinoma epithelial cell line A549 was cultured according to ATCC recommendations.

\subsection{Synthesis of hyaluronan-cisplatin (HA-Pt) conjugates}

HA (35,000 g/mol, $100 \mathrm{mg}$ ) and CDDP (45 mg) were dissolved in Milli-Q water (20 mL) and stirred in the dark for 3 days at ambient temperature (ca. $25^{\circ} \mathrm{C}$ ). The reaction mixture was filtered $\left(0.2 \mu \mathrm{m}\right.$ nylon membrane) and dialyzed against $\mathrm{ddH}_{2} \mathrm{O}$ (10,000 MWCO; Pierce, Rockford, IL) for $48 \mathrm{~h}$ at $4^{\circ} \mathrm{C}$. Following dialysis, the crude product was concentrated and stored as a $3.5 \mathrm{mg} / \mathrm{mL}$ solution, and the degree of CDDP substitution was determined on a 
platinum (Pt) basis by atomic absorption spectroscopy (AAS). The resulting conjugate is referred to as HA-Pt for clarity, although the conjugate is $\mathrm{Pt}\left(\mathrm{NH}_{3}\right)_{2}\left(\mathrm{H}_{2} \mathrm{O}\right) \mathrm{OOC}-\mathrm{HA}$ (mixture of mono- and diconjugated).

\subsection{In vitro drug release}

The in vitro release rate of the active hydrated form of cisplatin (cis- $\left[\mathrm{Pt}\left(\mathrm{NH}_{3}\right)_{2}\left(\mathrm{H}_{2} \mathrm{O}\right)_{2}{ }^{+}\right]$) from HA-Pt conjugate was determined in $\mathrm{ddH}_{2} \mathrm{O}$ or PBS. HA-Pt conjugate of known CDDP concentration was sealed a dialysis bag (MWCO 10,000, Pierce) and placed in a stirred water bath $\left(\mathrm{pH} 7.4,37^{\circ} \mathrm{C}\right)$ or PBS $\left(140 \mathrm{mM}, \mathrm{pH} 7.4,37^{\circ} \mathrm{C}\right)$. The bath volume $(3 \mathrm{~L})$ was replaced every $4 \mathrm{~h}$ and the sink conditions were maintained at $37^{\circ} \mathrm{C}$ and $\mathrm{pH}$ controlled by addition of $\mathrm{NaOH}$ and $\mathrm{HCl}$. Samples were taken from the dialysis bags at predetermined time points, and remaining Pt concentration was determined by AAS. As a control, free CDDP diffusion from the dialysis bag was also determined under the same sink conditions. All experiments were conducted in triplicate and the results expressed as mean \pm STD.

\subsection{Cell toxicity}

A549 cell line was seeded into 96-well plates (5000 cells/well) in Kaighn's Modified F12 medium supplemented with $10 \%$ fetal bovine serum and $1 \% \mathrm{~L}$-glutamine. After $24 \mathrm{~h}$, CDDP or HA-Pt was applied ( $n=12 ; 7$ concentrations) and at $72 \mathrm{~h}$ post-addition, resazurin blue in phosphate-buffered saline was applied to each well (final concentration of $5 \mu \mathrm{M}$ ). After $4 \mathrm{~h}$, the fluorescence was measured (ex $560 \mathrm{~nm}$, em $590 \mathrm{~nm}$; SpectraMax Gemini; Molecular Devices, Sunnyvale, CA), and the $\mathrm{IC}_{50}$ was determined as the midpoint between negative (no drug) and positive controls (no cells).

\subsection{Pharmacokinetics and tissue distribution in rodents}

Female Sprague-Dawley rats (250-300 grams) (Charles River Laboratories, Inc., Wilmington, MA) were housed with free food and water access and on $12 \mathrm{~h} \mathrm{light/dark} \mathrm{cycles} \mathrm{in} \mathrm{temperature}$ and humidity controlled rooms. The University of Kansas IACUC committee approved all animal surgical and experimental procedures.

All surgical tools were autoclaved and MRE-033 tubing (Braintree Scientific; Braintree MA) was ethylene oxide sterilized prior to use. Rats were anesthetized by isoflurane inhalation for surgical procedures. Atropine $(0.05 \mathrm{mg} / \mathrm{kg})$ was given subcutaneously to prevent overactive secretion of the trachea upon stimulation. The rat's body temperature was maintained at $37^{\circ} \mathrm{C}$ during surgical procedures. MRE-033 tubing was surgically implanted in the jugular vein. After exposing the trachea, a 25-gauge needle was used to make a small puncture in the trachea just below the cricoid cartilage. MRE-033 tubing was inserted through the hole and secured just above the bifurcation. Both cannulas were tunneled through to the back of the neck and the incision was closed. Buprenorphrine $(0.1 \mathrm{mg} / \mathrm{kg})$ was given as post-operative care. The rats were allowed to recover overnight before experimentation. For i.v. dosed rats, only a jugular cannula was implanted.

Prior to instillation of CDDP or HA-Pt, rats were anesthetized by isoflurane inhalation and positioned upright so that the lungs were in a vertical presentation. CDDP $(3.5 \mathrm{mg} / \mathrm{kg})$ or HA$\mathrm{Pt}(3.5 \mathrm{mg} / \mathrm{kg}$ equivalent of CDDP) in ca. $200 \mu \mathrm{L}$ of saline was slowly injected through the trachea cannula over $1 \mathrm{~min}$, followed by a saline chase to correct for the cannula dead volume (ca.10 $\mu \mathrm{L}$ ). The rat remained upright for the following $4 \mathrm{~min}$ and was then removed from anesthesia. Blood samples $(200 \mu \mathrm{L})$ were taken from the jugular cannula at $5 \mathrm{~min}, 0.5,1,2,4$, $6,8,12,24$, and up to $96 \mathrm{~h}$ post dose. Blood was transferred to vials containing $2 \mu \mathrm{L}$ of sodium heparin and centrifuged to obtain plasma. The plasma was stored at $-80^{\circ} \mathrm{C}$ until analysis. At 24 and $96 \mathrm{~h}$ post dose, the rats were euthanized by isoflurane overdose. Organs and lymph nodes were harvested, washed in $0.9 \%$ saline, and stored at $-80^{\circ} \mathrm{C}$ until analysis. 
Pharmacokinetic analysis was performed using data from individual rats for which the mean and standard error of the mean (S.E.M.) were calculated for each group using WinNonlin ${ }^{\circledR}$ software (Version 5.2, Pharsight Corporation, Mountain View, CA).

\subsection{Atomic absorption spectroscopy (AAS) for CDDP}

The in vitro release samples and plasma samples were diluted 200 -fold and 10 -fold in $0.1 \%$ nitric acid, respectively. Tissue samples $(100 \mathrm{mg})$ and lymph nodes $(10 \mathrm{mg})$ were digested in $4.5 \%$ nitric acid at $80^{\circ} \mathrm{C}$ for $2 \mathrm{~h}$ and then homogenized (Tissue Tearor; BioSpec Products Inc, Bartlesville, OK). All samples were centrifuged at 17,000 g for $20 \mathrm{~min}$ and the supernatants were analyzed by AAS.

The Pt concentrations in the release samples and plasma, tissue, and lymph node samples were analyzed on a Varian SpetrAA 220G atomic absorption spectometer (Palo Alto, CA, USA) with a graphite furnace and partition tubes. Testing samples $(21 \mu \mathrm{L})$ were injected by an autosampler, followed by addition of $0.1 \%$ nitric acid $(19 \mu \mathrm{L})$. A calibration curve of platinum concentration was determined from 0 to $450 \mathrm{ppb}$ in $0.1 \%$ nitric acid. The Pt recovery was measured by spiking plasma/tissue blanks with CDDP or HA-CDDP $(50 \mu \mathrm{g} / \mathrm{g})$ and processing as above. The furnace program was as follows: ramp 25 to $80^{\circ} \mathrm{C}$, hold $2 \mathrm{~s}$; ramp to $120^{\circ} \mathrm{C}$, hold $10 \mathrm{~s}$; ramp to $1000{ }^{\circ} \mathrm{C}$, hold $5 \mathrm{~s}$; ramp to $2700{ }^{\circ} \mathrm{C}$, hold $2 \mathrm{~s}$; cool to $25^{\circ} \mathrm{C}$ over $20 \mathrm{~s}$. The graphite partition tube was cleaned every 40 samples by baking at $2800^{\circ} \mathrm{C}$ for $7 \mathrm{~s}$. Argon was used as the injection and carrier gas.

\subsection{Lung tissue histology}

For histological examination of lung tissue after lung administration, rats were euthanized at $24 \mathrm{~h}$ post instillation of HA-Pt, CDDP, or HA in saline, as described above. The lungs were harvested and stored in $80 \%$ alcoholic formalin until analysis. Tissue processing for histology and examination was performed in a blinded manner by a third party pathologist before decoding.

\subsection{Statistics}

All tissue distribution and pharmacokinetic data were compared between CDDP (i.v. and pulmonary instillation) and HA-Pt (i.v. and pulmonary instillation) groups using the two-tailed student t-test. For all statistical analyses, $\mathrm{p}$ values less than 0.05 were considered significant.

\section{Results and Discussion}

\subsection{Synthesis of HA-Pt conjugates}

CDDP was conjugated to HA using a starting ratio of CDDP/HA ranging from 0.03 up to 0.70 . The conjugation efficiency decreased with the increase of CDDP/HA starting ratio due to the poor solubility of CDDP in water and possibly due to the crowding of Pt on the HA polymer at higher degrees of substitution and creation of hydrophobic regions. As shown in Table 1, the conjugation efficiency was significantly decreased from $50.8 \%(0.5 \mathrm{w} / \mathrm{w} \mathrm{CDDP} / \mathrm{HA})$ to $34.4 \%(0.7 \mathrm{w} / \mathrm{w} \mathrm{CDDP} / \mathrm{HA})$. The HA-Pt conjugate used in the following animal studies had a substitution degree of $25 \%$ (w/w). As shown in Fig. 1, one or more chlorides on CDDP can hydrolyze and then replaced by carboxylate(s) on HA. The resulting conjugate is referred to as HA-Pt for clarity, although the conjugate is $\mathrm{Pt}\left(\mathrm{NH}_{3}\right)_{2}\left(\mathrm{H}_{2} \mathrm{O}\right) \mathrm{OOC}-\mathrm{HA}$ (mixture of monoand diconjugated, Fig. 1). The released product is also referred to as CDDP for clarity and comparision to the free drug, although the released product is a mixture of hydrolyzed and chlorinated forms. 


\subsection{In vitro CDDP release}

The CDDP release rate was determined in PBS and water according to a reported protocol (Jeong et al., 2008; Nishiyama and Kataoka, 2001). The CDDP release profiles showed psuedo first order release kinetics with a half-life of $42 \mathrm{~h}$ in water and $10 \mathrm{~h}$ in PBS (Fig. 2). The $\mathrm{Cl}^{-}$ in PBS displaced CDDP rapidly and thus increased the release rate. The diffusion rate of free CDDP (Pt) from the dialysis tubing was also determined. More than $90 \%$ of CDDP moved across the dialysis membrane in $2 \mathrm{~h}$ (data not shown). A similar CDDP release profile from cisplatin-incorporated hyaluronic acid nanoparticles was observed by Jeong et al. (Jeong et al., 2008). Cisplatin was conjugated on to hyaluronan $\mathrm{COOH}$ groups via an ester bond (Fig. 1), which was reversible due to its low nucleophilicity; and in vivo CDDP was slowly released as its intact form from the HA-Pt conjugates.

\subsection{Cell toxicity}

HA-Pt conjugates had similar toxicities as compared to CDDP in the human lung cancer cell line A549. There was no significant difference in cell toxicity $\left(\mathrm{IC}_{50} 2 \mu \mathrm{g} / \mathrm{mL}\right.$, corresponding to $7 \mu \mathrm{M}$ ) between HA-Pt and CDDP (Fig. 3). IC $_{50}$ of CDDP in the A549 cell line was in good agreement with the previously reported values from Cafaggi $\left(\mathrm{IC}_{50} 6.87 \mu \mathrm{M}\right)(\mathrm{Cafaggi}$ et al., 2007) and Rabik ( $\mathrm{IC}_{50} 9.7 \mu \mathrm{M}$ ) (Rabik et al., 2008). HA had no toxicity to A549 over the concentration range examined (up to $10 \mathrm{mg} / \mathrm{mL}$; data not shown). These results suggest that the antitumor activity of CDDP was fully preserved after conjugation to HA. Over the time period of the toxicity study, nearly all of the platinum would be released from the HA conjugates. Agreeing with reported studies (Banzato et al., 2008;Brown, 2008), our results indicate that synergistic or antagonistic effects due to hyaluronan are not evident. Other studies determined that the conjugation of CDDP to gelatin or $\operatorname{poly}(\gamma, \mathrm{L}$-glutamic acid) reduced its cytotoxicity in vitro. As reported by Tseng et al. (Tseng et al., 2009), when CDDP was conjugated to gelatin, the $\mathrm{IC}_{50}$ value of gelatin-CDDP was 3.6-fold higher than free CDDP. Poly $(\gamma, \mathrm{L}$-glutamic acid)-cisplatin conjugate was less toxic than free CDDP in the human breast cancer cell line Bcap-37 (Ye et al., 2006).

\subsection{Pharmacokinetics and tissue distribution}

The Pt concentration in the plasma or tissues was determined by the AAS. The calibration curve was linear in the concentration range from 0 to $450 \mathrm{ppb}\left(\mathrm{R}^{2}>0.99\right)$, with a limit of detection of $5 \mathrm{ppb}$ and a limit of quantification of $10 \mathrm{ppb}$ (5\% standard deviation). The $\mathrm{Pt}$ recovery from HA-CDDP spiked tissues was: plasma $82 \pm 4 \%$ (mean \pm std); lymph nodes 92 $\pm 2 \%$; bladder $88 \pm 1 \%$; brain $94 \pm 0.3 \%$; heart $97 \pm 1 \%$; kidneys $98 \pm 1 \%$; liver $100 \pm 1 \%$; lung $94 \pm 1 \%$; muscle $95 \pm 1 \%$; spleen $97 \pm 1 \%$. The Pt recovery from CDDP spiked tissues was: plasma $80 \pm 3 \%$ (mean \pm std); lymph nodes $92 \pm 6 \%$; bladder $86 \pm 3 \%$; brain $93 \pm 10 \%$; heart $93 \pm 5 \%$; kidneys $100 \pm 2 \%$; liver $100 \pm 7 \%$; lung $95 \pm 8 \%$; muscle $100 \pm 5 \%$; spleen 96 $\pm 9 \%$.

Similar Pt tissue concentrations (Fig. 4A) were observed in brain, heart, kidney, liver, muscle and spleen $24 \mathrm{~h}$ post dose in both CDDP lung instillation (1.i.) and HA-Pt (1.i.) treated animals ( $\mathrm{n}=5$ CDDP 1.i.; $\mathrm{n}=3$ HA-Pt 1.i.). The total Pt concentration in the bladder was significantly higher in the CDDP 1.i. group $24 \mathrm{~h}$ post dose. At $96 \mathrm{~h}$, there were statistically significant differences in the Pt distribution in kidneys, liver and lungs for the HA-Pt lung instillation group (Fig. 4B). The lung accumulation of Pt was 1.5-fold and 0.8-fold higher in the HA-Pt 1.i. group compared with the CDDP 1.i. group $(\mathrm{p}<0.05)$ at $24 \mathrm{~h}$ and $96 \mathrm{~h}$, respectively. In order to compare the Pt distribution in tissues between the li. and i.v. routes, CDDP $(n=4)$ and HA$\mathrm{Pt}(\mathrm{n}=3)$ were also administered as an i.v. bolus dose. As shown in Fig. 4 for i.v. groups, significantly higher Pt concentrations were found in the liver and spleen but not in the lung tissues for the HAPt i.v. group at both $24 \mathrm{~h}$ and $96 \mathrm{~h}$. The Pt concentration in the bladder for the CDDP i.v. group at $24 \mathrm{~h}$ was higher than that of the HA-Pt group. The results of the tissue 
distribution study (Fig. 4) indicated that the HA-Pt 1.i. group had 5.7-fold and 1.2-fold higher lung Pt concentrations than the CDDP i.v. group, at $24 \mathrm{~h}$ and $96 \mathrm{~h}$, respectively.

The peak plasma concentrations $\left(\mathrm{C}_{\max }\right)$ for i.v. groups (both CDDP and HA-Pt) and the CDDP 1.i. group were achieved immediately post dose; while for the HA-Pt l.i. group, the $\mathrm{C}_{\max }$ reached its maximum at $24 \mathrm{~h}$ (Fig. 5). The $\mathrm{C}_{\max }$ values were 9.0-, 54.0- and 0.7-fold higher for the groups of CDDP i.v., HA-Pt i.v., CDDP 1.i., respectively, when compared to $\mathrm{C}_{\max }$ of the HAPt 1.i. group. The first order input rate $\left(\mathrm{K}_{\mathrm{a}}\right)$ in the HA-Pt l.i. group was significantly reduced compared to the other treatment groups; the Pt plasma concentration in the HA-Pt l.i. group gradually increased and reached a time to maximum concentration ( $\left.\mathrm{T}_{\max }\right)$ at $24 \mathrm{~h}$ (Fig. 5) and then entered the elimination phase. The Pt plasma concentrations in the HA-Pt 1.i. group were higher than the corresponding concentrations in the CDDP 1.i. group $4 \mathrm{~h}$ post dose.

Similar nodal distribution of Pt was found in the axillary and inguinal nodes at both $24 \mathrm{~h}$ and $96 \mathrm{~h}$ (Fig. 6) for the l.i. groups. The collected nodes included hilar, mediastinal, carinal, and aortic nodes, which are the major lung draining lymph nodes. The Pt nodal concentration in the HA-Pt 1.i. group, reported as $\mu \mathrm{g} / \mathrm{g}$ lymph node tissue, had a 1.9-fold increase compared to the CDDP 1.i. group at $24 \mathrm{~h}$ but showed no significant differences at $96 \mathrm{~h}$. The Pt concentrations in the draining lung surrounding nodes were similiar between CDDP i.v and HA-Pt i.v. groups. When CDDP or HA-Pt conjugates were given intravenously, the Pt preferentially accumulated in the axillary and inguinal nodes to a greater extent than the surrounding lung lymph nodes. The most significant finding of localized concentration was in the lung lymph nodes, where $\mathrm{Pt}$ was 1.1-fold higher in the HA-Pt l.i. group than the CDDP i.v. group at $24 \mathrm{~h}$.

In order to compare the relative nodal concentrations and non-specific organ uptake, the ratio of the Pt concentration in tissues to plasma was reported in Table 2. At $24 \mathrm{~h}$, tissue/plasma ratios for the HA-Pt i.v. group were slightly lower or similar to the ratios in the CDDP i.v. group, except for the liver. The HA-Pt l.i. group had lower Pt concentrations in all the tested organs compared to CDDP 1.i. group. This ratio in the surrounding nodes draining the lung was similar for all the i.v. groups and 1.i. groups. Due to the high molecular weight of HA $(35,000 \mathrm{~g} / \mathrm{mol})$ and the slow release of Pt from HA-Pt conjugates in the lung, the tissue/plasma ratio of the non-draining lymph nodes such as the axillary node and inguinal node was much lower in the HA-Pt 1.i. group than the CDDP 1.i. group. At 96 h, the HA-Pt 1.i. group had the lowest tissue/plasma ratio in all the organs and tested lymph nodes for the four treatment groups examined. Nephrotoxicity and neurotoxicity are clinically the most severe dose-limiting sideeffects of CDDP therapy. When comparing the tissue/plasma ratios in the brain and kidneys, the HA-Pt l.i. group had a smaller ratio in both organs at $24 \mathrm{~h}$ and $96 \mathrm{~h}$ compared to the CDDP i.v. group. Although the ratio in the lung was not significantly different between the groups of CDDP 1.i. and HA-Pt 1.i. at $24 \mathrm{~h}$, the ratios for the HA-Pt 1.i. group and CDDP i.v. group at 24 $\mathrm{h}$ were $15.42 \pm 2.70$ and $4.40 \pm 0.68$, respectively.

The relative discrepancy is partially explained by the much higher plasma AUC for 1.i. HA-Pt compared to other treatments, as 1.i. HA-Pt sustained much higher plasma concentrations of $\mathrm{Pt}$ at 24 and $96 \mathrm{~h}$ than the other treatments. As indicated in Fig. 5, the Pt plasma concentration at $96 \mathrm{~h}$ was $0.34 \pm 0.06$ and $1.24 \pm 0.17 \mu \mathrm{g} / \mathrm{mL}$ for the CDDP i.v. and HA-Pt l.i. groups, respectively. Thus the ratio of Pt in lung/plasma at $96 \mathrm{~h}$ for the HA-Pt l.i. group was only half of the value of the CDDP i.v. group. The increased plasma concentrations at later time points suggests that platinum is released slowly from the conjugates, which may reduce the acute toxicity of CDDP therapy as the input rate and high $\mathrm{C}_{\max }$ immediately after i.v. dosing is believed to lead to many of the toxic side-effects of chemotherapeutic agents (Chen and Hasumi, 1995;Ikeda et al., 1998;Kurihara et al., 1996;Launay-Vacher et al., 2008). 
The plasma platinum concentrations were modeled using non-compartmental modeling (WinNonlin ${ }^{\circledR}$ ); and the pharmacokinetic parameters (the volume of distribution, $\mathrm{V}_{\mathrm{z}}$; the area under the curve from time zero to $96 \mathrm{~h}, \mathrm{AUC}_{0-96}$; the total body clearance, $\mathrm{Cl}$; the peak plasma concentration, $\mathrm{C}_{\max }$; the mean residence time, MRT; and the terminal elimination half-life, $t_{1 / 2}$ ) were calculated and evaluated. CDDP i.v. exhibited a significantly higher $V_{z}$ compared to the HA-Pt i.v., likely due to the extensive tissue binding of free CDDP as opposed to a polymer bound CDDP conjugate even though the half-life of CDDP release in vitro is a mere $10 \mathrm{~h}$. With regard to the clearance of CDDP, the free CDDP $\left(\mathrm{M}_{\mathrm{w}}=300.05 \mathrm{~g} / \mathrm{mol}\right)$ was cleared from the body more rapidly compared to HA-bound CDDP (i.v. groups). It is likely due to the smaller size and lower molecular weight and water solubility of CDDP, facilitating glomerular filtration through the kidneys. In contrast, the active form of the drug can only be cleared after cleavage from the hyaluronan polymer backbone. These pharmacokinetic parameters were very similar to the results of free CDDP and CDDP-incorporating PEG-P(Glu) micelles using the same noncompartment model (Uchino et al., 2005). In addition, the $\mathrm{AUC}_{0-96}$ of 1.i. HAPt treated group demonstrated a 0.6 -fold increase in relative to i.v. CDDP treated group, which could be explained by the sustained release characteristics of the conjugate over time. The mean residence time and the terminal elimination half-time of HA-Pt 1.i. group were 1.3-fold and 1.0-fold higher than the CDDP i.v. group. The data from the lung instillation studies suggests 'flip-flop' pharmacokinetics of the HA-Pt conjugate, indicating the absorption of the conjugate is the rate-limiting step and dissolution of the conjugate may be slow. In this case the plasma concentration time curve is proportional to the rate of absorption. Therefore, the i.v. and l.i. data demonstrated non-parallel slopes in the terminal elimination phase. It is likely due to the depot effect of the polymer-drug conjugate, preventing the rapid distribution of the drug into the system. There remained a significant amount of drug in the plasma at the conclusion of the $96 \mathrm{~h}$ pharmacokinetic study as the absorption rate constant is much slower than the elimination rate constant. The controlled release fashion of the HA-Pt conjugate when used clinically could be significantly beneficial for patients with lung cancers by reducing the treatment frequency through a increased dosing interval which could ultimately shorten the hospital stay.

\subsection{Lung tissue histology}

Histological examination of lung tissue after 1.i. administration revealed areas of moderate inflammation characterized by infiltration of neutrophils, edema, and exudation of protein rich fluid when either HA-Pt or CDDP were dosed (Fig. 7 A and B). Although patchy areas of lung tissue elicited areas of inflammation, the majority of the airways remained clear. These doses were also compared to lung tissue with only HA in saline dosed, which showed only mild inflammation with a few small areas of neturophil infiltration (Fig. 7 C). With reduced inflammation occurring when only HA was dosed, it is suggested that the majority of lung inflammation was due to CDDP. Although lung inflammation occurred in these studies, it is important to note that independent of what was instilled; all histological data revealed that the animals were diagnosed with pneumonia. This suggests a major role of the method of delivery in these histological results. Although studies have suggested that instilling at a volume of ca. $1 \mathrm{~mL} / \mathrm{kg}$ body weight is suitable for delivery, this form of pulmonary delivery is not clinically relevant. Even for jet nebulizers where up to $10 \mathrm{~mL}$ is delivered per $70 \mathrm{~kg}$ patients only ca. $0.14 \mathrm{mg} / \mathrm{kg}$ is delivered to the lung. Aerosol inhalation would be more suitable and practical delivery method that may increase and optimize drug distribution throughout the lung. The instillation method used here only concentrated the drug in portions of the lung eliciting patchy areas of inflammation. An aerosolized delivery of HA-Pt would most likely result in more optimal drug distribution in the lung as well as deposition deeper in the lung periphery with increased drainage to lung lymph nodes. 


\section{Conclusions}

In conclusion, hyaluronan-cisplatin conjugate was successfully synthesized and the in vitro antitumor activity of cisplatin was fully preserved after conjugation. Compared to conventional CDDP i.v. infusion, the HA-Pt lung instillation group had not only higher Pt accumulations in the lung tissues and the draining lung surrounding nodes but also demonstrated a sustained release plasma profile with a reduced peak plasma concentration.

In future studies, we will examine the in vivo efficacy in orthotopic rodent models of lung xenograft. In addition, a nebulized formulation is currently being developed that may further optimize delivery and disposition. If these results are translatable into the clinic, a HA-Pt localized pulmonary treatment could possibly lead to a relatively non-invasive, more effective lung cancer treatment, which could have clinical utility in lung cancer patients.

\section{Acknowledgments}

The authors acknowledge NIH R21CA132033, American Cancer Society Research Scholar Grant RSG-08-133-01CDD, and NIH-COBRE P20 RR015563 for partial support of this project.

\section{Abbreviations}

$\begin{array}{ll}\text { AUC } & \text { area-under-the-curve } \\ \text { CDDP } & \text { cis-diamminedichloroplatinum (II), cisplatin } \\ \text { HA-Pt } & \text { Hyaluronan CDDP conjugate } \\ \mathrm{C}_{\max } & \text { peak plasma concentration } \\ \text { 1.i. } & \text { lung instillation }\end{array}$

\section{References}

Banzato A, Bobisse S, Rondina M, Renier D, Bettella F, Esposito G, Quintieri L, Melendez-Alafort L, Mazzi U, Zanovello P, Rosato A. A paclitaxel-hyaluronan bioconjugate targeting ovarian cancer affords a potent In vivo therapeutic activity. Clin. Cancer Res 2008;14:3598-3606. [PubMed: 18519794]

Brown DB, Cai SR, Fundakowski CE, Zamboni WC, Strychor S, McLeod HL. Pharmacokinetics after endovascular lung perfusion with cisplatin. J. Vasc. Interv. Radiol 2006;17:883-888. [PubMed: 16687755]

Brown TJ. The development of hyaluronan as a drug transporter and excipient for chemotherapeutic drugs. Curr. Pharm. Biotechnol 2008;9:253-260. [PubMed: 18691086]

Cafaggi S, Russo E, Stefani R, Leardi R, Caviglioli G, Parodi B, Bignardi G, De Totero D, Aiello C, Viale M. Preparation and evaluation of nanoparticles made of chitosan or N-trimethyl chitosan and a cisplatin-alginate complex. J. Control. Release 2007;121:110-123. [PubMed: 17601625]

Cai S, Xie YM, Bagby TR, Cohen MS, Forrest ML. Intralymphatic chemotherapy using a hyaluronancisplatin conjugate. J. Surg. Res 2008;147:247-252. [PubMed: 18498877]

Carrick S, Ghersi D, Wilcken N, Simes J. Platinum containing regimens for metastatic breast cancer. Cochrane Database Syst Rev 2004:CD003374.

Chen JT, Hasumi K. Pharmacokinetic analysis of platinum in the continuous CDDP-CBDCA treatment; its relation to the changes of blood biochemistry. Gan To Kagaku Ryoho 1995;22:653-657. [PubMed: 7717717]

Chu G. Cellular-Responses to Cisplatin - the Roles of DNA-Binding Proteins and DNA-Repair. J. Biol. Chem 1994;269:787-790. [PubMed: 8288625] 
Devarajan P, Tarabishi R, Mishra J, Ma Q, Kourvetaris A, Vougiouka M, Boulikas T. Low renal toxicity of lipoplatin compared to cisplatin in animals. Anticancer Res 2004;24:2193-2200. [PubMed: 15330160]

Fraser JR, Laurent TC. Turnover and metabolism of hyaluronan. Ciba Found Symp 1989;143:41-53. discussion 53-49, 281-285. [PubMed: 2680348]

Gagnadoux F, Hureaux J, Vecellio L, Urban T, Le Pape A, Valo I, Montharu J, Leblond V, BoisdronCelle M, Lerondel S, Majoral C, Diot P, Racineux JL, Lemarie E. Aerosolized chemotherapy. J. Aerosol Med. Pulm. Drug Deliv 2008;21:61-69. [PubMed: 18518832]

Hotta K, Matsuo K, Ueoka H, Kiura K, Tabata M, Tanimoto M. Meta-analysis of randomized clinical trials comparing cisplatin to carboplatin in patients with advanced non-small-cell lung cancer. J. Clin. Oncol 2004;22:3852-3859. [PubMed: 15326195]

Ihde DC, Mulshine JL, Kramer BS, Steinberg SM, Linnoila RI, Gazdar AF, Edison M, Phelps RM, Lesar M, Phares JC, Grayson J, Minna JD, Johnson BE. Prospective Randomized Comparison of HighDose and Standard-Dose Etoposide and Cisplatin Chemotherapy in Patients with Extensive-Stage Small-Cell Lung-Cancer. J. Clin. Oncol 1994;12:2022-2034. [PubMed: 7931470]

Ikeda K, Terashima M, Kawamura H, Takiyama I, Koeda K, Takagane A, Sato N, Ishida K, Iwaya T, Maesawa C, Yoshinari H, Saito K. Pharmacokinetics of cisplatin in combined cisplatin and 5fluorouracil therapy: a comparative study of three different schedules of cisplatin administration. Jpn J Clin Oncol 1998;28:168-175. [PubMed: 9614438]

Jeong YI, Kim ST, Jin SG, Ryu HH, Jin YH, Jung TY, Kim IY, Jung S. Cisplatin-incorporated hyaluronic acid nanoparticles based on ion-complex formation. J Pharm Sci 2008;97:1268-1276. [PubMed: 17674407]

Junior ADC, Vieira FP, De Melo VJ, Lopes MTP, Silveira JN, Ramaldes GA, Garnier-Suillerot A, Pereira-Maia EC, De Oliveira MC. Preparation and cytotoxicity of cisplatin-containing liposomes. Brazilian J. Med. Biol. Res 2007;40:1149-1157.

Kim ES, Lu C, Khuri FR, Tonda M, Glisson BS, Liu D, Jung M, Hong WK, Herbst RS. A phase II study of STEALTH cisplatin (SPI-77) in patients with advanced non-small cell lung cancer. Lung Cancer 2001;34:427-432. [PubMed: 11714540]

Kurihara N, Kubota T, Hoshiya Y, Otani Y, Ando N, Kumai K, Kitajima M. Pharmacokinetics of cisdiamminedichloroplatinum (II) given as low-dose and high-dose infusions. J Surg Oncol 1996;62:135-138. [PubMed: 8649040]

Launay-Vacher V, Rey JB, Isnard-Bagnis C, Deray G, Daouphars M. Prevention of cisplatin nephrotoxicity: state of the art and recommendations from the European Society of Clinical Pharmacy Special Interest Group on Cancer Care. Cancer Chemother. Pharmacol 2008;61:903-909. [PubMed: 18317762]

Nishiyama N, Kataoka K. Preparation and characterization of size-controlled polymeric micelle containing cis-dichlorodiammineplatinum(II) in the core. J Control Release 2001;74:83-94. [PubMed: 11489486]

Nishiyama N, Okazaki S, Cabral H, Miyamoto M, Kato Y, Sugiyama Y, Nishio K, Matsumura Y, Kataoka K. Novel cisplatin-incorporated polymeric micelles can eradicate solid tumors in mice. Cancer Res 2003;63:8977-8983. [PubMed: 14695216]

Perng RP, Chen YM, MingLiu J, Tsai CM, Lin WC, Yang KY, WhangPeng J. Gemcitabine versus the combination of cisplatin and etoposide in patients with inoperable non-small-cell lung cancer in a phase II randomized study. J. Clin. Oncol 1997;15:2097-2102. [PubMed: 9164223]

Rabik CA, Fishel ML, Holleran JL, Kasza K, Kelley MR, Egorin MJ, Dolan ME. Enhancement of Cisplatin [cis-Diammine Dichloroplatinum (II)] Cytotoxicity by O-6-Benzylguanine Involves Endoplasmic Reticulum Stress. J. Pharmacol. Exp. Ther 2008;327:442-452. [PubMed: 18664592]

Selting K, Waldrep JC, Reinero C, Branson K, Gustafson D, Kim DY, Henry C, Owen N, Madsen R, Dhand R. Feasibility and safety of targeted cisplatin delivery to a select lung lobe in dogs via the AeroProbe (R) Intracorporeal Nebulization Catheter. J. Aerosol Med. Pulm. Drug Deliv 2008;21:255-268. [PubMed: 18759657]

Tseng CL, Su WY, Yen KC, Yang KC, Lin FH. The use of biotinylated-EGF-modified gelatin nanoparticle carrier to enhance cisplatin accumulation in cancerous lungs via inhalation. Biomaterials 2009;30:3476-3485. [PubMed: 19345990] 
Uchino H, Matsumura Y, Negishi T, Koizumi F, Hayashi T, Honda T, Nishiyama N, Kataoka K, Naito S, Kakizoe T. Cisplatin-incorporating polymeric micelles (NC-6004) can reduce nephrotoxicity and neurotoxicity of cisplatin in rats. British Journal of Cancer 2005;93:678-687. [PubMed: 16222314]

Ye H, Jin L, Hu R, Yi Z, Li J, Wu Y, Xi X, Wu Z. Poly(gamma,L-glutamic acid)-cisplatin conjugate effectively inhibits human breast tumor xenografted in nude mice. Biomaterials 2006;27:5958-5965. [PubMed: 16949149]

Zatloukal P, Petruzelka L, Zemanova M, Kolek V, Skrickova J, Pesek M, Fojtu H, Grygarkova I, Sixtova D, Roubec J, Horenkova E, Havel L, Prusa P, Novakova L, Skacel T, Kuta M. Gemcitabine plus cisplatin vs. gemcitabine plus carboplatin in stage IIIb and IV non-small cell lung cancer: a phase III randomized trial. Lung Cancer 2003;41:321-331. [PubMed: 12928123] 


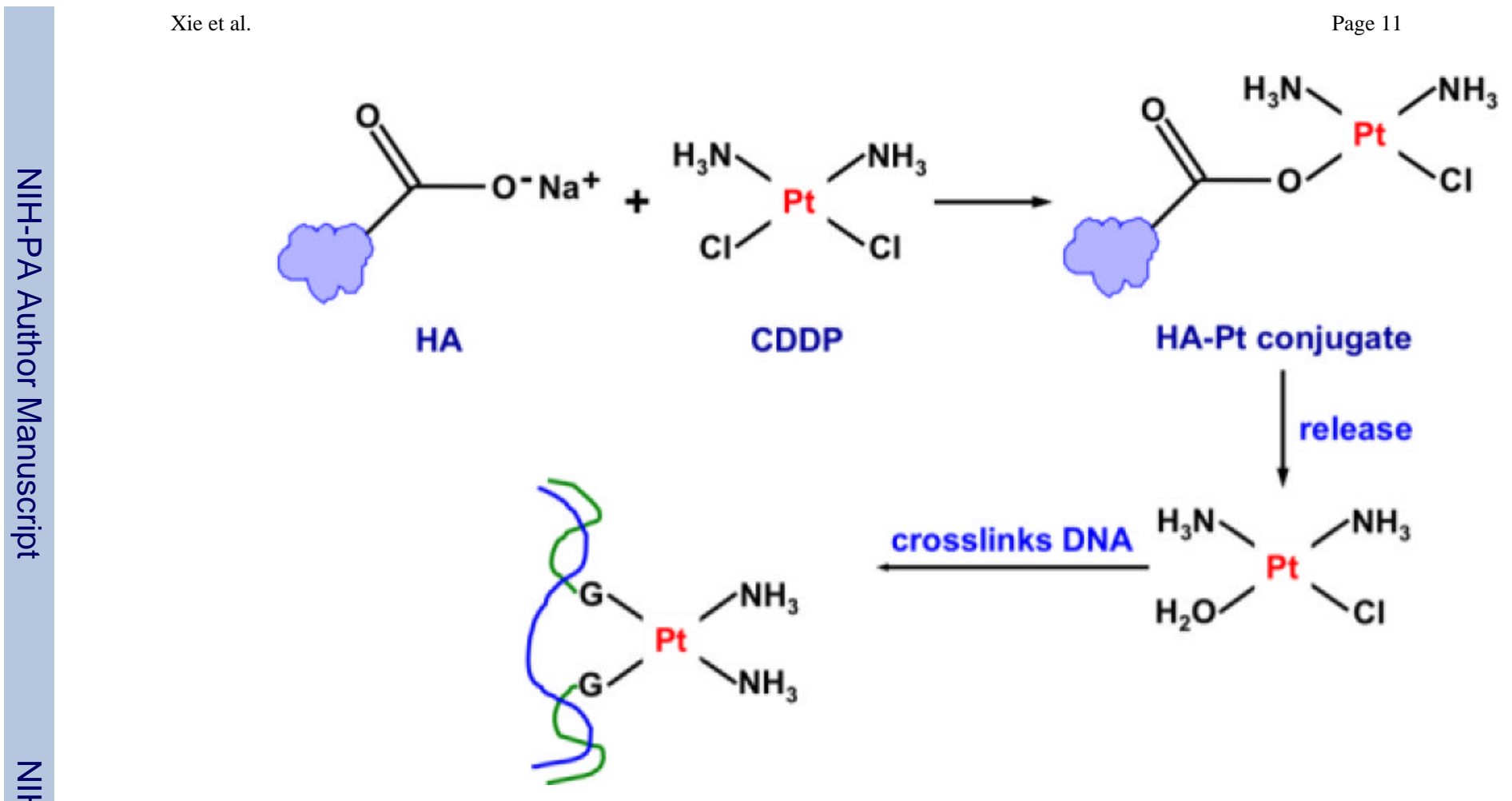

Figure 1.

Synthesis and release of HA-Pt conjugates 


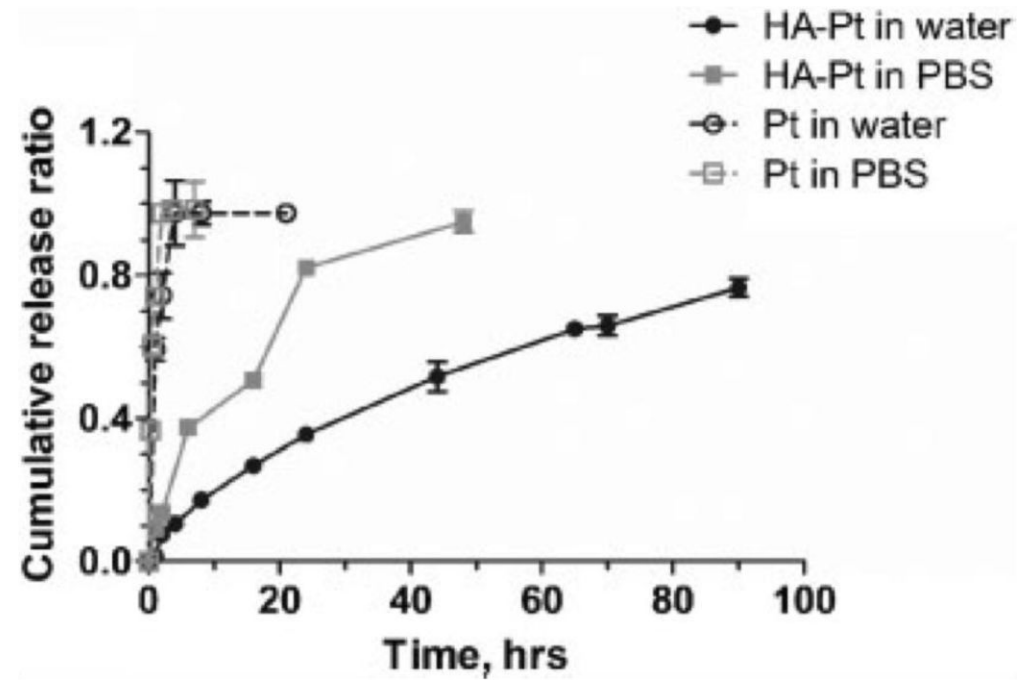

Figure 2.

In vitro release of platinum from HA-Pt conjugates 


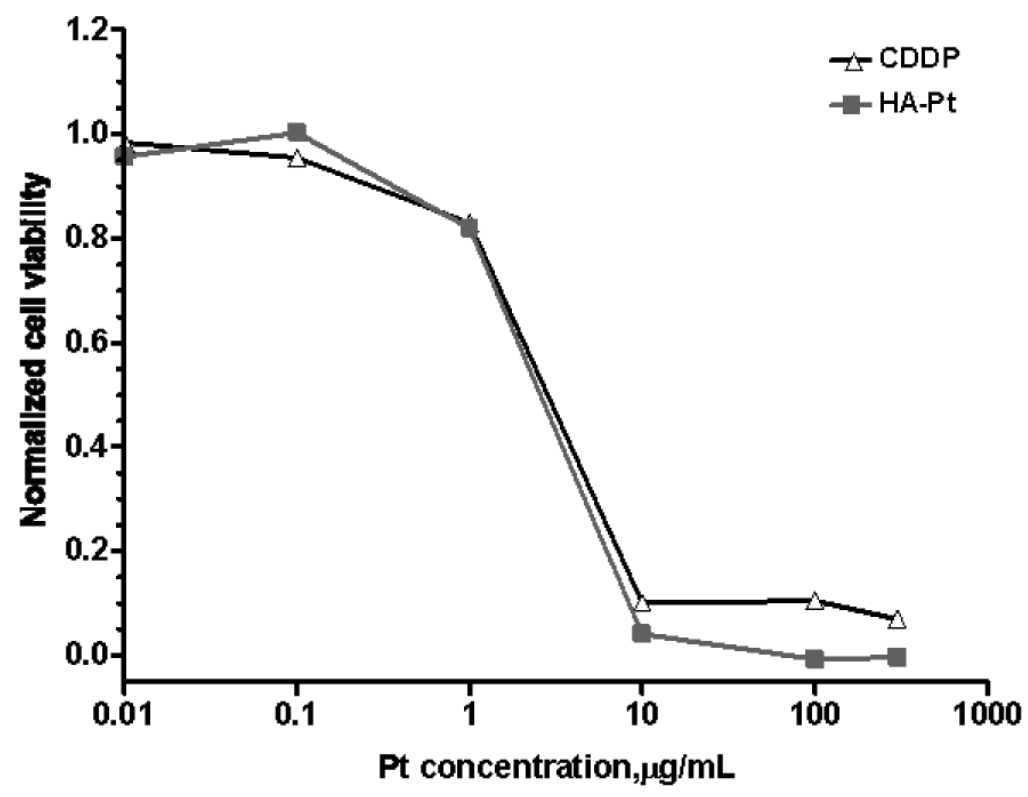

Figure 3.

Cell toxicity of CDDP and HA-Pt conjugates 

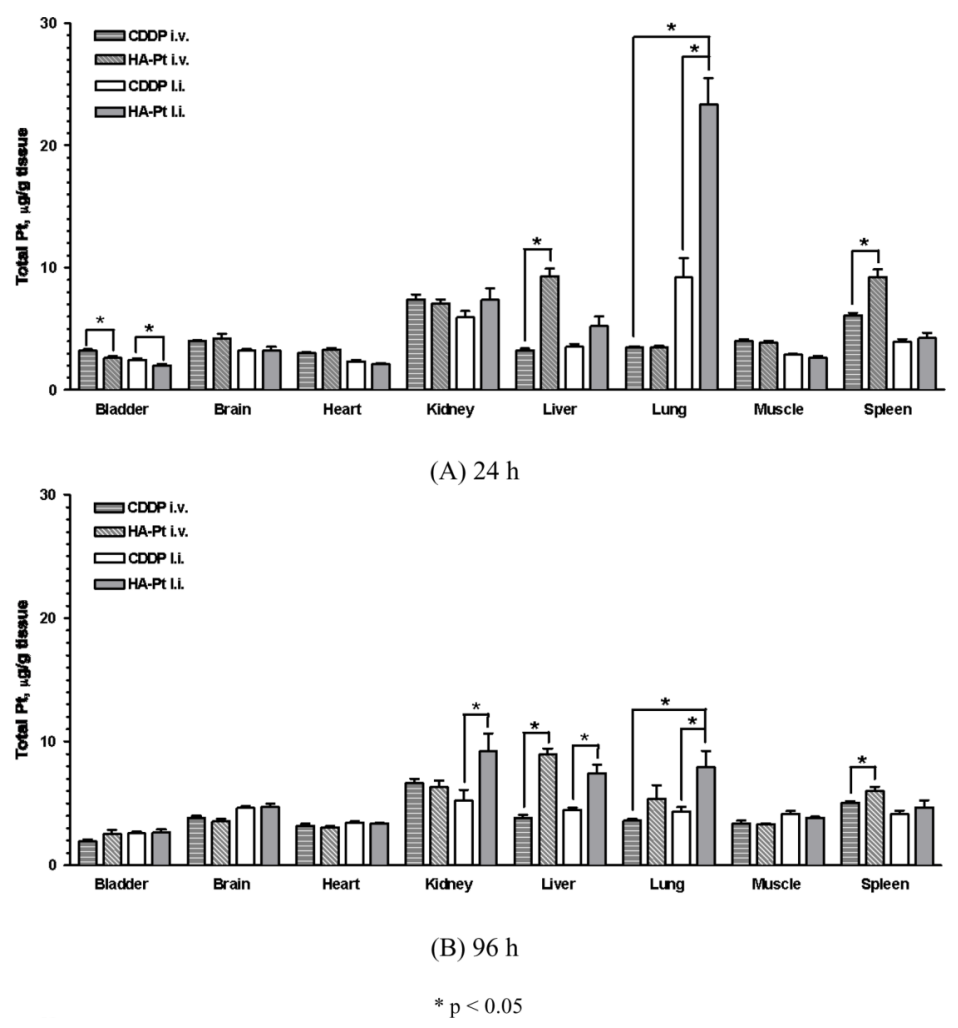

Figure 4.

Tissue distribution of CDDP and HA-Pt conjugates 


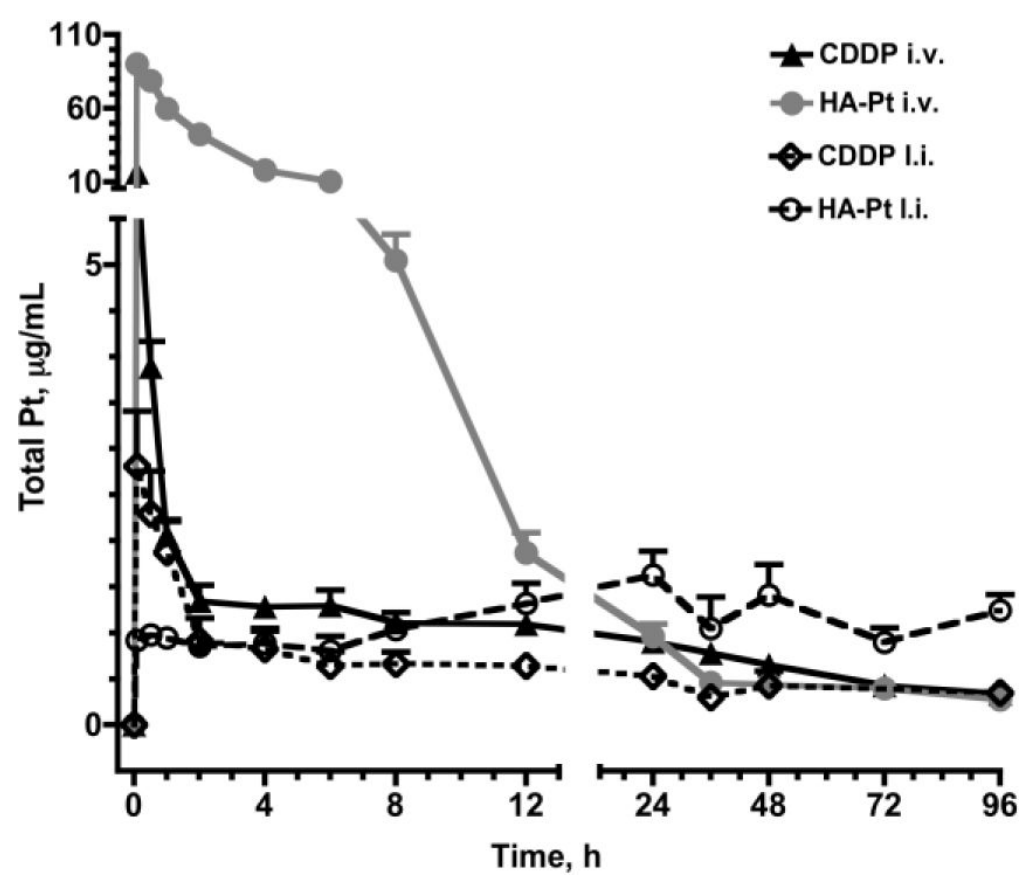

Figure 5.

Pharmacokinetics intravenous vs. lung instillation 


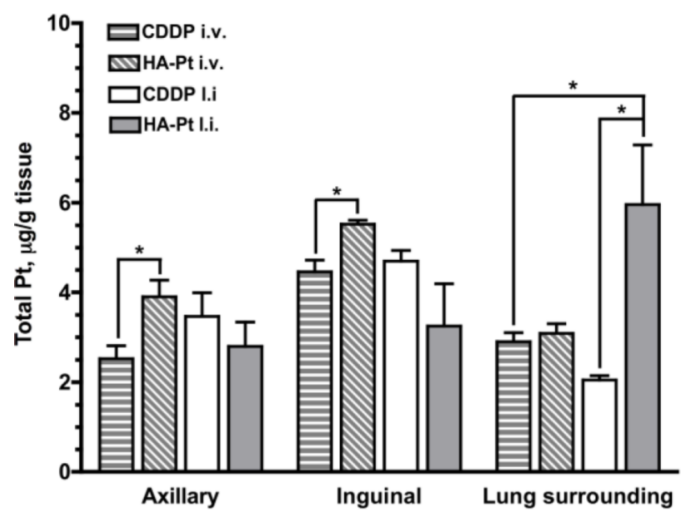

(A) $24 \mathrm{~h}$

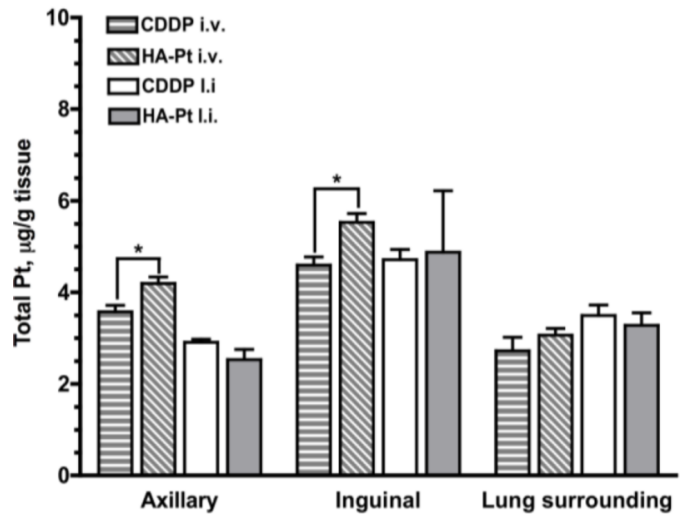

(B) $96 \mathrm{~h}$

$* \mathrm{p}<0.05$

Figure 6.

Lymph node distribution intravenous vs. lung instillation 

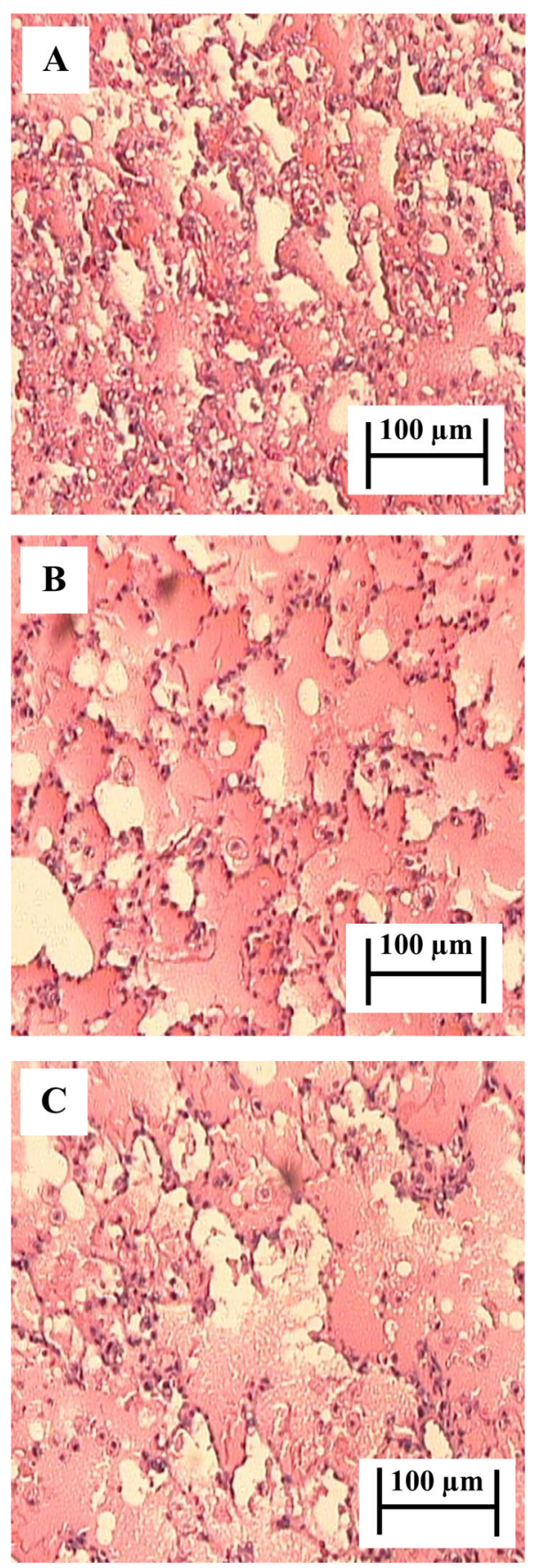

Figure 7.

Lung histology after instillation of (A) HA-Pt, (B) CDDP, and (C) HA in saline (24 h post dose) 
Table 1

Conjugation efficiency of HA-Pt

\begin{tabular}{ccc}
\hline CDDP Added (CDDP/HA, w/w) & CDDP Conjugated (CDDP/HA, w/w) & Conjugation Efficiency $^{*}(\boldsymbol{\%})$ \\
\hline 0.030 & 0.022 & 73.3 \\
0.080 & 0.040 & 50.0 \\
0.150 & 0.086 & 57.3 \\
0.200 & 0.119 & 59.5 \\
0.300 & 0.149 & 49.7 \\
0.400 & 0.210 & 52.5 \\
0.500 & 0.254 & 50.8 \\
0.600 & 0.263 & 43.8 \\
0.700 & 0.241 & 34.4 \\
\hline
\end{tabular}

* Conjugation efficiency was calculated as (CDDP added/CDDP conjugated)* $100 \%$ 


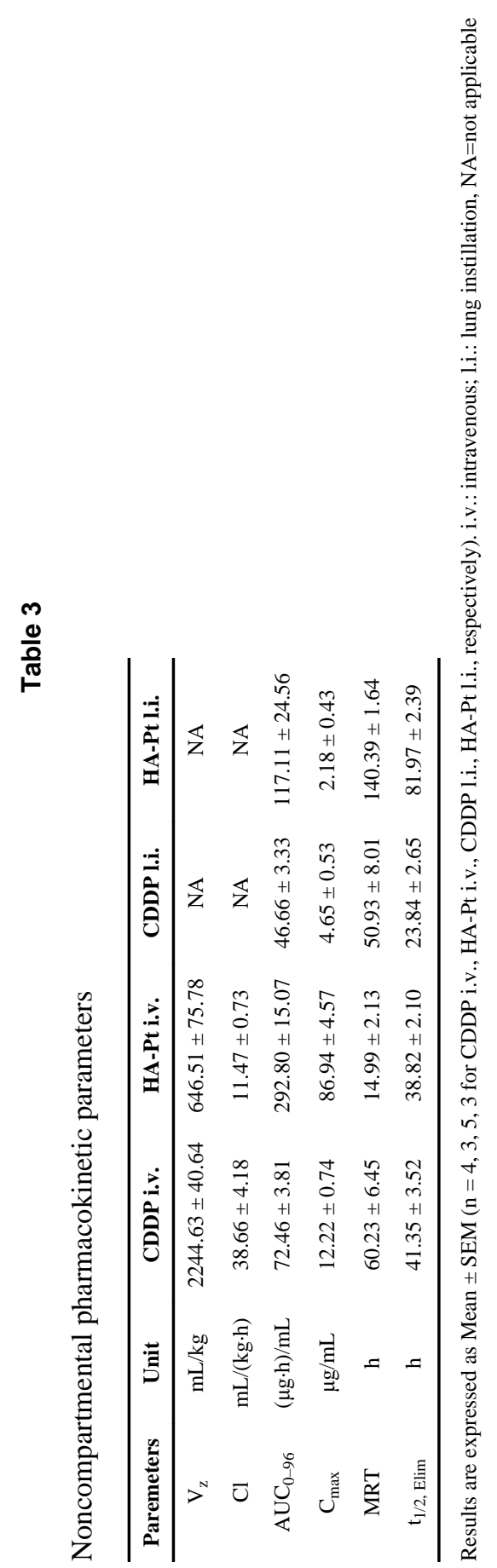

Int J Pharm. Author manuscript; available in PMC 2011 June 15. 